\title{
Prognosis of EGFR-mutant advanced lung adenocarcinoma patients with different intrathoracic metastatic patterns
}

\author{
Fang $\mathrm{Hu}^{1}$,\#, Bo Zhang1,\#, Changhui $\mathrm{Li}^{1}$, Jianlin $\mathrm{Xu}^{1}$, Huimin Wang1, Ping Gu${ }^{1}$, Xiaoxuan Zheng1, Wei Nie${ }^{1}$, \\ Yinchen Shen ${ }^{1}$, Hai Zhang1, Ping Hu², Xueyan Zhang1, ${ }^{1}$ \\ 1. Department of Pulmonary, Shanghai Chest Hospital, Shanghai Jiao Tong University, Shanghai 200030, PR China. \\ 2. Internal Medicine, Shangyu People's Hospital, Shangyu, Zhejiang Province 312300, PR China. \\ \#Contributed equally to this work. \\ $\square$ Corresponding author: Xueyan Zhang, Department of Pulmonary, Shanghai Chest Hospital, Shanghai Jiao Tong University, No.241 Huaihai West Road, \\ Xuhui District, Shanghai 200030, China. E-mail: zxychest@163.com; Tel: +86 18017321319; Fax: +86 62821990 \\ (c) Ivyspring International Publisher. This is an open access article distributed under the terms of the Creative Commons Attribution (CC BY-NC) license \\ (https://creativecommons.org/licenses/by-nc/4.0/). See http://ivyspring.com/terms for full terms and conditions.
}

Received: 2018.07.18; Accepted: 2019.01.05; Published: 2019.01.29

\begin{abstract}
Introduction: Lung cancer diagnosed solely with the presence of intrathoracic metastases is classified as Mla. However, intrathoracic metastases can be further divided into different patterns. The objective of our study was to analyze the differences in survival between the different metastatic patterns of intrathoracic metastases in lung adenocarcinoma patients who have epidermal growth factor receptor (EGFR) mutations.

Materials and Methods: Patients who were diagnosed only with intrathoracic metastasis between March 2011 and October 2016 and had EGFR-mutations were selected for this study. Prognosis was determined based on metastatic patterns by univariate and multivariate analysis.

Results: A total of 137 patients ( 60 patients who only had pleural metastasis [Group A], 44 patients who only had contralateral lung metastasis [Group B] and 33 patients who had both pleural and contralateral lung metastasis with or without pericardial effusion [Group C]) were selected for this in the study. The median OS (overall survival) time was 38.1 (95\%confidence interval $[\mathrm{Cl}]$ : 27.8-48.4), 35.7(95\% Cl: 23.4-48.0), and 29.7(95\%Cl: 22.8-36.6) months for Group A, Group B, and Group C, respectively $(p=0.037)$. Multivariate analysis demonstrated that Group A and Group B had higher OS compared to Group $C$ (hazard ratio $[H R]=0.524,95 \% \mathrm{Cl}: 0.307-0.894, p=0.018 ; \mathrm{HR}=0.473,95 \% \mathrm{Cl}: 0.241-0.931, p=0.030$, respectively) among lung adenocarcinoma patients with EGFR mutations. With regard to patients with pleural or contralateral metastasis only, OS benefit $(p=0.579)$ was not significant between the two groups. Subgroup analysis demonstrated that OS benefit in Group A was significant in patients with N0-1 disease and 21L858R mutations but not in EGFR exon 19 deletions, N2-3 stage or T3-4 stage patients.

Conclusion: The prognosis of EGFR-mutant lung adenocarcinoma patients diagnosed only with intrathoracic metastasis was different, indicating that Mla staging should be refined.
\end{abstract}

Key words: adenocarcinoma, intrathoracic metastases, overall survival.

\section{Introduction}

Lung cancer is one of the most common malignant tumors that seriously endanger human health [1]. Based on the data published in 2015 by CA-A Cancer Journal for Clinicians, there are 1.82 million new cases of lung cancer worldwide each year. Nearly 1.59 million patients died from lung cancer every year, of which 0.49 million were women and 1.1 million were men [2]. Non-small cell lung cancer (NSCLC) accounts for more than $80 \%$ of all pathological types of lung cancer. For early NSCLC, surgery is the best treatment option. However, the vast majority of lung cancer patients are usually in advanced stage when diagnosed and lose the chance for surgery $[3,4]$.

In clinical practice, tumor size, lymph node metastasis and distant metastasis (TNM) classification 
are always used to stage tumors. This is performed to facilitate treatment decision and for prognosis prediction [5-7]. The 8th TNM classification, which was issued in a revised form by the International Association for the Study of Lung Cancer (IASLC) in 2015, defined M1a as tumors that have distant metastasis in the contralateral lung or have pleural/pericardial nodule/malignant effusion [7]. There are multiple metastatic patterns in intrathoracic metastases, such as simple pleural metastases, simple contralateral lung nodules, bilateral pulmonary nodules, pericardial effusions, and simultaneous metastases at these sites [8]. However, patients were classified as M1a when intrathoracic metastases occurred in the 8th edition of the TNM classification of lung cancer, regardless of the patterns of intrathoracic metastasis [7]. Several retrospective and small prospective studies have indicated that single or multiple extrathoracic metastases had a worse prognosis compared to limited intrathoracic metastasis [9-11]. However, it is unclear for comparisons of prognosis for different patterns of intrathoracic metastasis in patients with EGFR mutant lung adenocarcinoma in recent years. Thus, the purpose of this study was to determine the prognostic value of the different types of intrathoracic metastases in lung adenocarcinoma patients with EGFR mutations.

\section{Materials and Methods}

\section{Patients}

The Institutional Review Board of Shanghai Chest Hospital approved this study. Informed consent for the study was obtained from all patients. All patients were diagnosed with lung adenocarcinoma had intrathoracic metastasis in our hospital between March 2011 and October 2016. In addition, all patients included in our study were with M1a metastasis when initially diagnosed. Patients diagnosed with intrathoracic metastases were divided into three groups: Group A (pleural metastasis only), Group B (contralateral lung metastasis only) and Group C (had both pleural and contralateral lung metastasis with or without pericardial effusion). NSCLC staging was performed according to the 8th TNM classification. The inclusion criteria were as follows: (1) Advanced lung adenocarcinoma with intrathoracic metastasis only. (2) All patients included were diagnosed histopathologically or cytologically. (3) With EGFR mutation and treated with EGFR-tyrosine kinase inhibitors (EGFR-TKIs: erlotinib, gefitinib or icotinb). (4) A systematic examination was performed before treatment. The clinical characteristics included sex, age at diagnosis, smoking status, EGFR mutation type, local consolidative therapy history (LCT, including surgery or radiotherapy for local metastatic lesions, such as bone, brain or other sites metastatic sites, which occurred after disease progression), performance status, $\mathrm{T}$ stage, $\mathrm{N}$ stage, brain metastasis, T790M mutation, treatment with Osimertinib.

\section{Clinical assessments}

First generation EGFR-TKI included gefitinib (250mg/times; one time/day), erlotinib (150mg/ times; one time/day) and icotinib $(125 \mathrm{mg} /$ times; three times/day). Chest computed tomography (CT), brain magnetic resonance imaging, bone scanning, abdominal B ultrasonic examination or whole body fluorodeoxyglucose (FDG) tumor imaging or FDG PET-CT were performed for all patients for initial staging evaluation. The nature of pleural fluid was assessed by pleural effusion cytology. Pleural nodules were diagnosed by chest CT, PET-CT, or biopsy of the chest wall nodules. OS time was calculated from the date of diagnosis of lung adenocarcinoma with intrathoracic metastases to the date of death or last follow-up visit. Progression-free survival (PFS) of first-line EGFR-TKIs was defined as the date from the initiation of TKIs therapy until the date of progression or last follow-up visit (June 15, 2018).

\section{Follow-up period}

Follow-up was conducted either by patients visiting the hospital for review or through telephone conversation. Clinical follow-up examinations included imaging, routine laboratory and physical examinations. Follow-up examinations were performed every 4-12 weeks. The total follow-up time was 87 months and the median follow-up time was 35.9 months. The follow-up rate was $86.7 \%$.

\section{Statistical analysis}

Clinical information were analyzed using $\chi^{2}$ tests or Fisher's exact tests, where appropriate. OS was calculated by the Kaplan-Meier method, and independent prognostic factors were assessed by Cox proportional hazards regression analysis. A Cox proportional hazard multivariable model was used for overall survival to determine the risk of death in lung adenocarcinoma patients with EGFR-mutations who received EGFR-TKI. Comparisons among the groups were performed using the Log-rank test. The level of significance was set to 0.05 . For pair-wise comparisons between the three groups, Bonferroni correction was adopted and the corrected $P$ value was 0.0167 (corrected $\mathrm{P}=0.05 / 3 \approx 0.0167$ ). SPSS statistical software version 24 was used for all statistical analyses. 


\section{Results}

\section{Patient characteristics}

A total of 137 patients were selected and analyzed based on the inclusion criteria. Patients selection was performed as shown in Figure S1. Characteristics of the entire patient cohort and each subgroup category are summarized in Table 1 . The $x^{2}$ test showed that clinical data such as age, sex, smoking history, EGFR mutation type, and LCT history were balanced among Group A, Group B and Group C ( $>>0.05)$ (Table 1).

\section{Univariate Analyses for OS}

Univariate analysis showed that simultaneous metastasis of the contralateral lung and pleura $(\mathrm{P}=0.012)$, smoker $(\mathrm{P}=0.004)$, other EGFR mutation status $(P=0.020), \quad N 2-3$ category $(P=0.018)$, brain metastasis $(\mathrm{P}=0.004)$, no treatment with osimertinib $(\mathrm{P}=0.00)$ were significantly associated with poorer OS. However, age, sex, LCT history, primary lung cancer treatment, $\mathrm{T}$ stage and different lines of EGFR TKIs had no statistical significance (Table 2).

The Log-rank $p$ was 0.037 and chi square $\left(X^{2}\right)$ value was 6.589 for overall comparisons of the three groups (Figure 1). The median OS of the three groups were 38.1months (95\%CI: 27.8-48.4, Group A), 35.7months (95\%CI: 23.4-48.0, Group B) and 29.7months (95\%CI: 22.8-36.6, Group C). Pairwise comparisons showed that patients who only had pleural metastasis had a significantly better OS compared to patients who had simultaneous metastasis of the contralateral lung and pleura (38.1 months, 95\%CI, 27.8-48.8 vs. 29.7 months, 95\%CI, 22.8-36.6, $\left.\chi^{2}=6.404, \mathrm{p}=0.011\right)$. A trend for OS was observed between the Group B and Group C (35.7months, $95 \% \mathrm{CI}, 23.4-48.0$ vs. 29.7 months, $95 \% \mathrm{CI}$, 22.8-36.6, $\chi^{2}=3.187, \mathrm{p}=0.074$ ) (Figure 1). No significant difference was found between Group A and Group B $\left(\chi^{2}=0.308, p=0.579\right)$. Moreover, patients without malignant pleural effusion experienced a significantly better OS compared with those who had (Figure 2).

Table 1. Demographic data of 137 patients and comparison of clinical characteristics between three groups

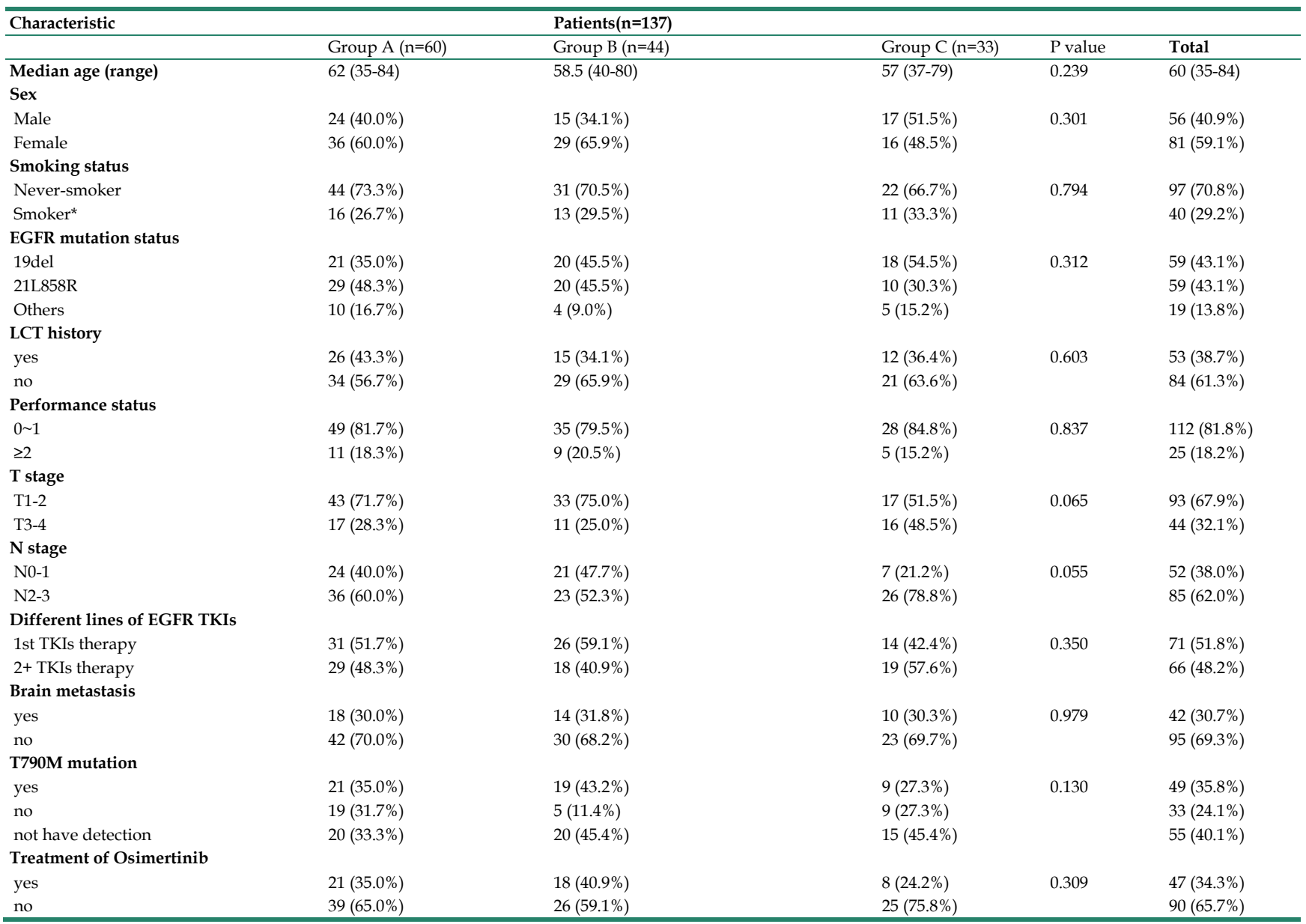

Abbreviations: EGFR, epidermal growth factor receptor; LCT, Local consolidative therapy

* The definition of "smoker" in our study means the patient who has smoked >100 cigarettes during their lifetime. 
Table 2. Univariate Analyses of Clinical Parameters on Overall Survival Outcomes

\begin{tabular}{|c|c|c|c|}
\hline Factor & & $\begin{array}{l}\text { Univariate Analysis } \\
\text { on OS }\end{array}$ & \\
\hline & Median OS $(95 \% \mathrm{CI})$ & Hazard Ratio (OS) & P Value \\
\hline \multicolumn{4}{|l|}{ Metastasis sites } \\
\hline Pleural & $\begin{array}{l}38.1(95 \% \mathrm{CI}, \\
27.8-48.4)\end{array}$ & $\begin{array}{l}0.538 \text { (95\%CI, } \\
0.330-0.877)\end{array}$ & 0.012 \\
\hline Contralateral lung & $\begin{array}{l}35.7(95 \% \mathrm{CI}, \\
23.4-48.0)\end{array}$ & $\begin{array}{l}0.625 \text { (95\%CI, } \\
0.370-1.054)\end{array}$ & 0.074 \\
\hline Both & $\begin{array}{l}29.7(95 \% \mathrm{CI}, \\
22.8-36.6)\end{array}$ & 1 & \\
\hline \multicolumn{4}{|l|}{ Age } \\
\hline$\leq 60$ & $\begin{array}{l}38.0(95 \% \mathrm{CI}, \\
32.1-43.9)\end{array}$ & $\begin{array}{l}0.955(95 \% \mathrm{CI}, \\
0.640-1.425)\end{array}$ & 0.820 \\
\hline$>60$ & $\begin{array}{l}34.5(95 \% \mathrm{CI}, \\
28.8-40.2)\end{array}$ & 1 & \\
\hline \multicolumn{4}{|l|}{ Sex } \\
\hline Male & $\begin{array}{l}31.8(95 \% \mathrm{CI}, \\
21.9-41.7)\end{array}$ & $\begin{array}{l}1.409 \text { (95\%CI, } \\
0.941-2.110)\end{array}$ & 0.094 \\
\hline Female & $\begin{array}{l}38.1(95 \% \mathrm{CI}, \\
34.9-41.3)\end{array}$ & 1 & \\
\hline \multicolumn{4}{|l|}{ Smoking status } \\
\hline Smoker & $\begin{array}{l}30.0(95 \% \mathrm{CI}, \\
23.0-37.0)\end{array}$ & $\begin{array}{l}1.853(95 \% \mathrm{CI}, \\
1.207-2.846)\end{array}$ & 0.004 \\
\hline Never-smoker & $\begin{array}{l}38.4(95 \% \mathrm{CI}, \\
30.1-46.7)\end{array}$ & 1 & \\
\hline \multicolumn{4}{|c|}{ EGFR mutation status } \\
\hline 19del & $\begin{array}{l}38.0(95 \% \mathrm{CI}, \\
34.7-41.3)\end{array}$ & $\begin{array}{l}0.503(95 \% \mathrm{CI}, \\
0.282-0.896)\end{array}$ & 0.020 \\
\hline 21L858R & $\begin{array}{l}37.0(95 \% \mathrm{CI}, \\
32.0-42.0)\end{array}$ & $\begin{array}{l}0.651(95 \% \mathrm{CI}, \\
0.363-1.169)\end{array}$ & 0.151 \\
\hline Others & $\begin{array}{l}22.1(95 \% \mathrm{CI}, \\
16.0-28.2)\end{array}$ & 1 & \\
\hline \multicolumn{4}{|l|}{ LCT history } \\
\hline yes & $\begin{array}{l}38.1(95 \% \mathrm{CI}, \\
34.6-41.6)\end{array}$ & $\begin{array}{l}0.824(95 \% \mathrm{CI}, \\
.546-1.244)\end{array}$ & 0.353 \\
\hline no & $\begin{array}{l}31.8(95 \% \mathrm{CI}, \\
22.6-41.0)\end{array}$ & 1 & \\
\hline \multicolumn{4}{|l|}{$\begin{array}{l}\text { Primary lung cancer } \\
\text { treatment }\end{array}$} \\
\hline Surgical & $\begin{array}{l}39.1(95 \% \mathrm{CI}, \\
26.7-51.5)\end{array}$ & $\begin{array}{l}0.799(95 \% \mathrm{CI}, \\
0.534-1.197)\end{array}$ & 0.275 \\
\hline Nonsurgical & $\begin{array}{l}33.7(95 \% \mathrm{CI}, \\
26.9-40.5)\end{array}$ & 1 & \\
\hline \multicolumn{4}{|l|}{ T stage } \\
\hline T1-2 & $\begin{array}{l}35.7(95 \% \mathrm{CI}, \\
31.0-40.4)\end{array}$ & $\begin{array}{l}0.857 \text { (95\%CI, } \\
0.562-1.307)\end{array}$ & 0.473 \\
\hline
\end{tabular}

\begin{tabular}{|c|c|c|c|}
\hline Factor & & $\begin{array}{l}\text { Univariate Analysis } \\
\text { on OS }\end{array}$ & \\
\hline & Median OS $(95 \% \mathrm{Cl})$ & Hazard Ratio (OS) & P Value \\
\hline T3-4 & $\begin{array}{l}37.0(95 \% \mathrm{CI}, \\
25.4-48.6)\end{array}$ & 1 & \\
\hline \multicolumn{4}{|l|}{$\mathrm{N}$ stage } \\
\hline N0-1 & $\begin{array}{l}51.2(95 \% \mathrm{CI}, \\
36.4-66.0)\end{array}$ & $\begin{array}{l}0.605(95 \% \mathrm{CI}, \\
0.396-0.923)\end{array}$ & 0.018 \\
\hline $\mathrm{N} 2-3$ & $\begin{array}{l}31.0(95 \% \mathrm{CI}, \\
23.6-38.4)\end{array}$ & 1 & \\
\hline \multicolumn{4}{|c|}{$\begin{array}{l}\text { Different lines of EGFR } \\
\text { TKIs }\end{array}$} \\
\hline 1st TKIs therapy & $\begin{array}{l}37.0(95 \% \mathrm{CI}, \\
32.7-41.6)\end{array}$ & $\begin{array}{l}0.867(95 \% \mathrm{CI}, \\
0.582-1.292)\end{array}$ & 0.483 \\
\hline 2+ TKIs therapy & $\begin{array}{l}33.7(95 \% \mathrm{CI}, \\
26.1-41.3)\end{array}$ & 1 & \\
\hline \multicolumn{4}{|l|}{ Brain metastasis } \\
\hline yes & $\begin{array}{l}31.0(95 \% \mathrm{CI}, \\
26.1-36.0)\end{array}$ & $\begin{array}{l}1.821(95 \% \mathrm{CI}, \\
1.202-2.75)\end{array}$ & 0.004 \\
\hline no & $\begin{array}{l}38.4(95 \% \mathrm{CI}, \\
28.7-48.1)\end{array}$ & 1 & \\
\hline \multicolumn{4}{|c|}{ Treatment of Osimertinib } \\
\hline yes & $\begin{array}{l}55.0(95 \% \mathrm{CI}, \\
46.4-63.6)\end{array}$ & $\begin{array}{l}0.388 \text { (95\%CI, } \\
0.245-0.613)\end{array}$ & 0.000 \\
\hline no & $\begin{array}{l}27.5(95 \% \mathrm{CI}, \\
20.4-34.1)\end{array}$ & 1 & \\
\hline
\end{tabular}

In patients with an exon 21L858R mutation, pairwise comparisons showed that Group A had a better OS versus Group C (39.1 months vs. 26.7months, $\chi^{2}=5.777, p=0.016$ ). While a trend was found but not significant between the Group B and Group C patients (31.8 months vs. 26.7 months, $\left.\chi^{2}=3.330, p=0.068\right)$ (Figure S2). The OS of the Group A, Group B and Group C for the 59 patients with a deletion in exon 19 (19del) were 48.8 months, 33 months, 35.5 months, respectively. No significant differences were found among the three groups who had in 19del mutations (Figure S3).

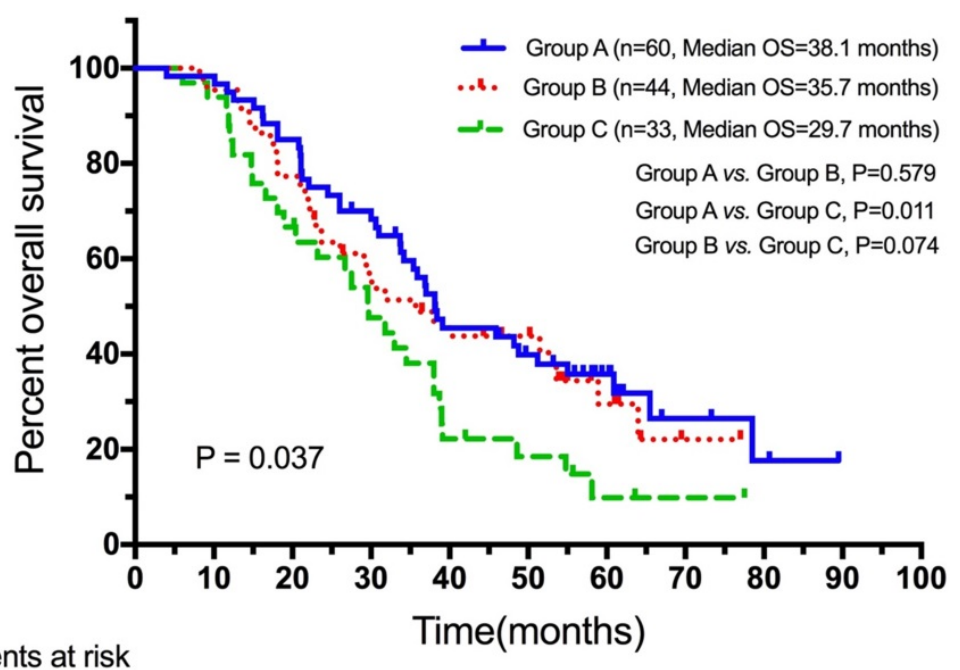

Patients at risk

\begin{tabular}{|c|c|c|c|c|}
\hline Group A 5 & 50 & 25 & 11 & 2 \\
\hline Group B 4 & 34 & 17 & 6 & 0 \\
\hline Group C 3 & 22 & 7 & 2 & 0 \\
\hline
\end{tabular}

Figure 1: OS for Group A, Group B and Group C patients. Abbreviations: OS, overall survival. 


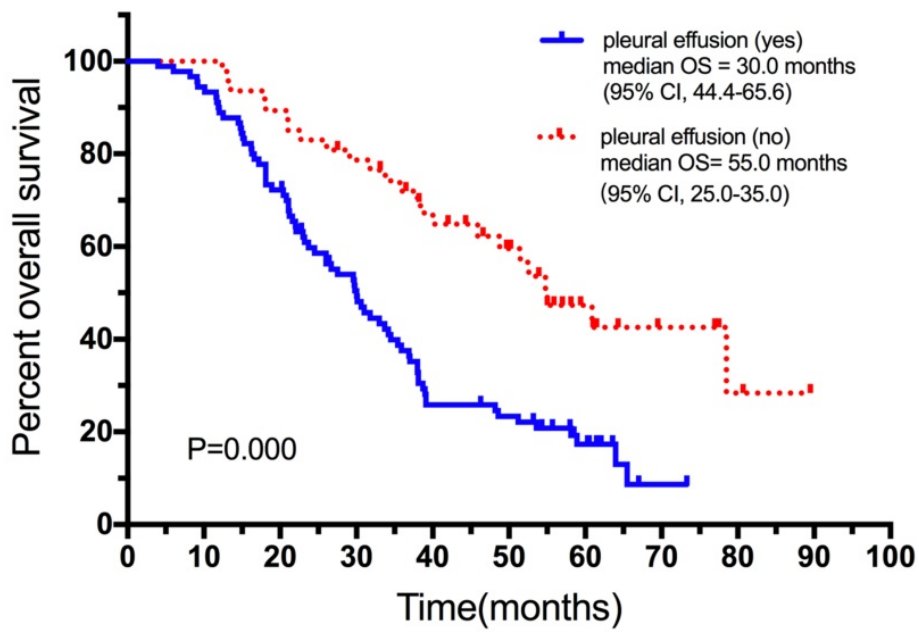

Figure 2: OS survival curve for patients with and without pleural effusion. Abbreviations: OS, overall survival

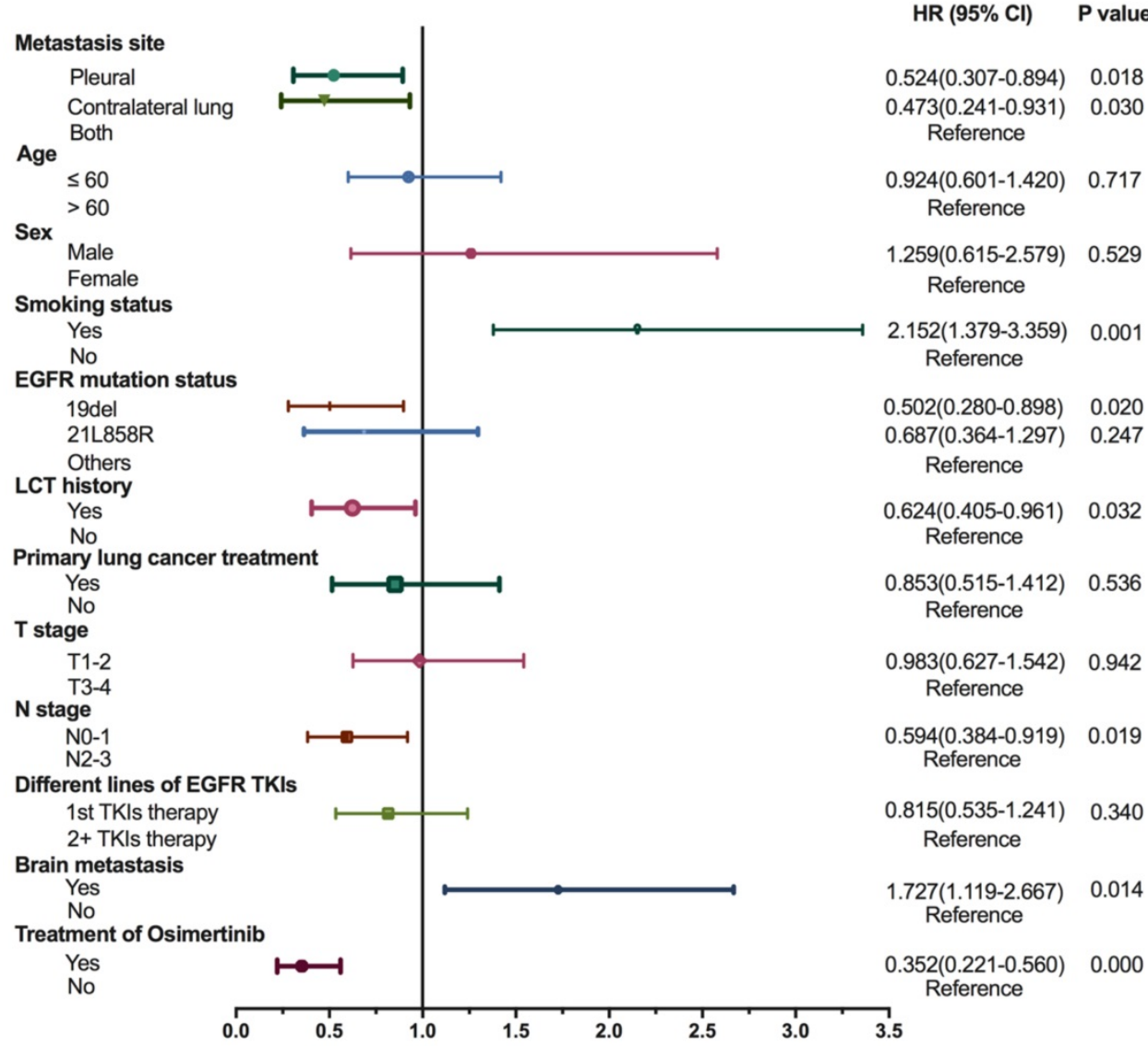

Figure 3: Forest Plot of Cox Proportional Hazard Multivariable Modeling on Overall Survival for lung adenocarcinoma patients with EGFR mutation who received EGFR-TKI. The covariates that are adjusted in the multivariate Cox model included metastasis site, age, sex, smoking status, EGFR mutation status, LCT history, primary lung cancer treatment, T stage, N stage, different lines of EGFR TKIs, brain metastasis and treatment with Osimertinib. Abbreviations: EGFR, epidermal growth factor receptor; TKI, tyrosine kinase inhibitor; LCT, local consolidative therapy; HR, hazard ratios.

\section{Multivariate analysis for OS}

For multivariate analysis, variables of clinical importance (age, sex, LCT history, primary lung cancer treatment, different lines of EGFR TKIs) and those with significant associations confirmed by univariate analysis (metastasis site, smoking status, $\mathrm{N}$ stage, brain metastasis, treatment of Osimertinib) underwent a Cox proportional hazard multivariable modeling to predict each outcome separately. The results demonstrated a significant survival benefit for Group A (HR=0.524, 95\% CI: 0.307-0.894, $\mathrm{p}=0.018$ ) and Group B (HR=0.473, 95\%CI: 0.241-0.931, $\mathrm{p}=0.030)$ compared to Group $\mathrm{C}$ among lung adenocarcinoma patients with EGFR mutation (Figure 3). By multivariate analysis, OS was significantly higher in 
non-smoking, brain metastasis free and Osimertinib treated patients. N0-1, 19del EGFR and LCT treatment were also associated with improved survival. Multivariate analysis also demonstrated that age, sex, primary lung cancer surgery, $\mathrm{T}$ stage and the different lines of EGFR-TKIs were not independent prognostic factors for OS (Figure 3).

\section{PFS of first-line EGFR-TKIs}

The PFS for first-line EGFR-TKI for Group A, Group B, and Group C patients were 16.9 months $(\mathrm{n}=31,95 \%$ CI: $15.3-18.5), 11.5$ months $(\mathrm{n}=26,95 \% \mathrm{CI}$ : 7.6-14.4), and 12.6 months ( $\mathrm{n}=14,95 \% \mathrm{CI}$ : 8.1-14.7), respectively. Patients who only had pleural metastasis showed a trend for longer PFS for first-line EGFR-TKIs when compared to the patients who had both pleural and contralateral lung metastasis with or without pericardial effusion $(p=0.02$, Figure 4$)$. No significant differences were found between the contralateral lung metastasis only patients and the other two groups of patients (Figure 4).

\section{Subgroup analysis}

Subgroup analysis showed that Group A had a longer tread for OS compared to Group C (38.4 months, 95\% CI: 26.5-50.3 vs. 29.6 months, 95\% CI: 20.9-38.3; $p=0.031$ ) among patients with $\mathrm{T} 1-2$ stage disease (Figure 5A). Patients with N0-1 stage disease, a significant survival benefit in the Group A $(60.9$ months, 95\% CI: 42.9-78.9) was observed compared to Group C (29.6 months, 95\% CI: 24.2-35.0; $p=0.011$; Figure 5C). Patients who were T3-4 and N2-3 stage disease, the survival difference was not significant for the three groups (Figure 5B, D).

\section{Discussion}

It is largely unknown what the prognostic differences are among patients with multiple metastatic patterns of intrathoracic metastasis lung adenocarcinoma patients with epidermal growth factor receptor (EGFR) mutations. In addition to investing the influence of different intrathoracic metastasis patterns on prognosis, this study also examined the most relevant prognostic factors, such as smoking status, EGFR mutational status, brain metastasis, age, sex, LCT history, primary lung cancer treatment, and different lines of EGFR TKIs. Our study used the Bonferroni correction, a rigorous statistical method which was considered efficient to avoid overestimation and was used to decrease Type 1 error of multiple testing. Using this correction, the positive findings were reduced and the false negative results were increased on multivariate analysis for OS.

Smoking status and $\mathrm{N}$ stage are well-known prognostic factors for lung cancer [12, 13]. In addition, LCT history, brain metastasis and treatment with Osimertinib have also been considered as important clinical prognostic factors [14, 15]. This study demonstrated that different metastatic patterns of intrathoracic metastases were also had prognostic value. In addition to being easy to keep track, we believe that these metastatic patterns should be considered in clinical practice. However, subgroup analysis demonstrated that the OS benefit for Group A was significant in patients with N0-1 disease but not in patients with N2-3 stage and T3-4 stage disease. We inferred that the poorer prognosis for N2-3 stage and T3-4 stage patients might have diminished the differences between the metastatic groups.

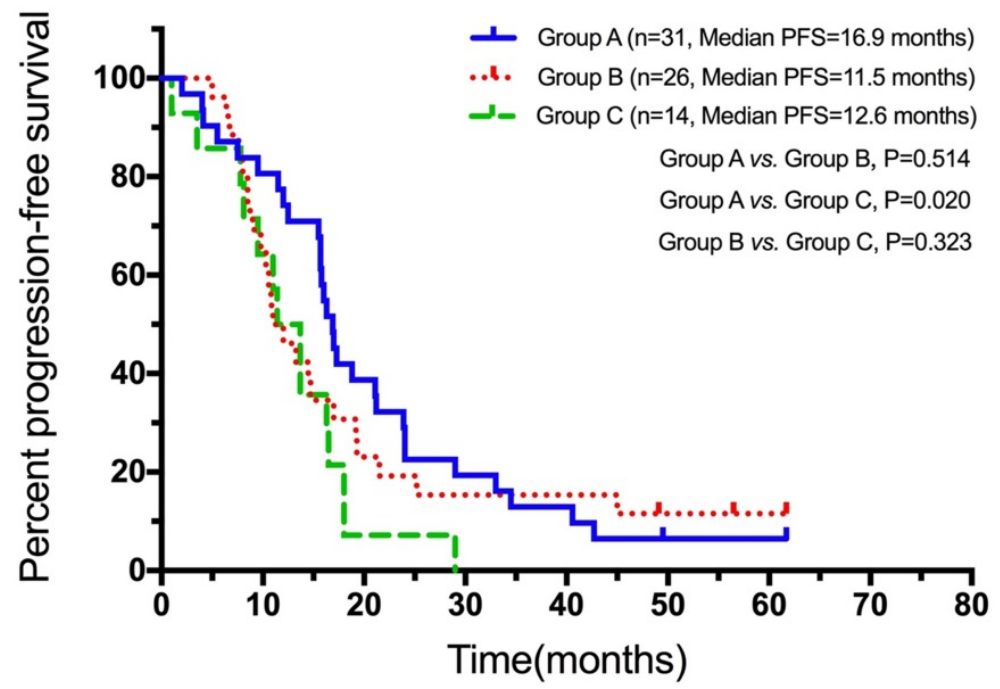

Figure 4: PFS for first-line EGFR-TKIs for Group A, Group B, and Group C patients. Abbreviations: PFS, progression-free survival. 

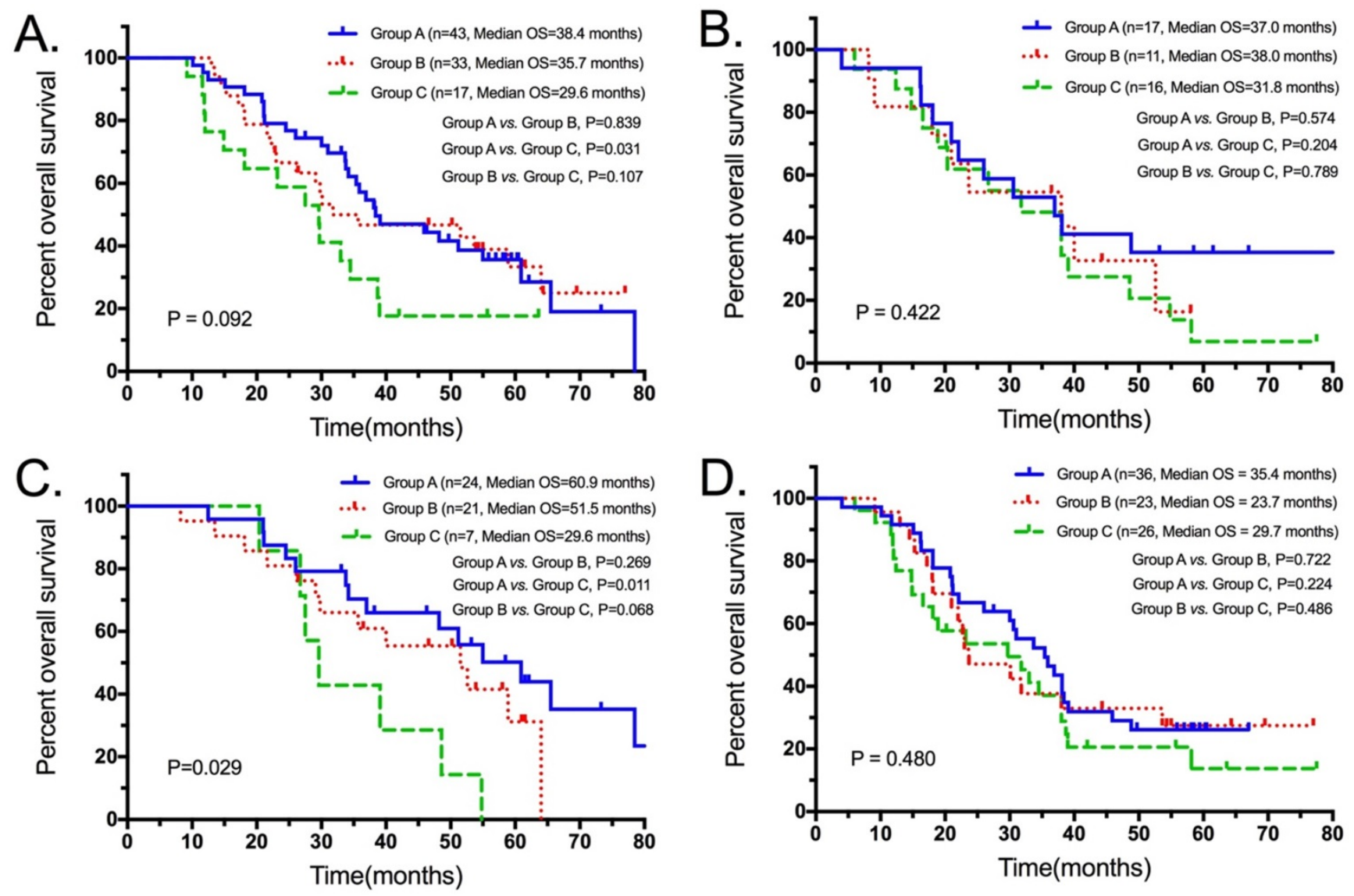

Figure 5: OS for Group A, Group B and Group C among the subgroups of T1-2 (A), T3-4 (B), N0-1 (C) and N2-3 (D) patients. Abbreviations: OS, overall survival.

Additionally, subgroup analysis showed that the difference between Group A and Group C were not statistically significant among patients with T1-2 stage disease. This negative result may be caused by Bonferroni correction, which was too rigorous and considered efficient in avoiding overestimation, while it reduced the positive findings. Moreover, the small sample size for each subgroup may have affected the statistical analysis. The OS for the three cohorts in those with exon 21L858R mutation patients were consistent with the entire patient cohort. However, for patients with a deletion in exon 19, the three groups did not show statistical differences for survival. This result may be partly explained by the inherent biological and prognostic differences between EGFR exon 19 deletion patients and 21L858R mutant patients. Based on previous studies, lung adenocarcinoma patients with a deletion in exon 19 showed significantly better efficacy for EGFR-TKIs treatment compared to the patients with an exon 21L858R mutation [16, 17]. Since patients with a deletion in exon 19 had a better therapeutic effect for EGFR-TKIs, this may, to a certain extent, covered up the differences in prognosis for the different metastatic patterns. A recent meta-analysis performed by Wang $\mathrm{H}$ et al. showed that NSCLC patients with the exon 19 deletions had higher response rate to tyrosine kinase inhibitors and better overall survival compared to NSCLC patients with 21L858R, suggesting that the improved prognosis for patients in the exon 19del group may reduce the differences between the metastatic groups [18].

Malignant pleural effusion is present in approximately $50 \%$ of lung cancer patients at a later stage of the disease [19]. Patients with pleural metastases are often accompanied with malignant pleural effusion. The presence of malignant pleural effusion usually indicates the poor prognosis and a shorter survival time as this study demonstrated [20, 21]. Solid pleural metastases of lung cancer without pleural effusion are defined as dry pleural dissemination. Most of the dry pleural dissemination are interlobar fissure metastases, and may relate to the location of the interlobar pleura, which is between the two lung lobes [21]. Studies have shown that patients with malignant pleural effusion have poorer prognosis compared to dry pleural metastases [19, 21, 22]. The results from this study support these previous observations.

The TNM classification system attempts to roughly assess the whole-body tumor burden by categorizing primary tumor size and local 
involvement, extent of nodal disease, and distant metastases [23, 24]. However, along with disease aggravation, the accuracy of the TNM classification system as a surrogate for overall tumor burden would collapse [24]. For example, a patient with only a single intrathoracic metastatic site would have the same stage as a patient with diffuse intrathoracic metastatic disease. Although neither patients would be suitable for surgery, their prognosis and therapy may not be the same. Moreover, tumor burden varies with different metastatic patterns for intrathoracic metastases. Simultaneous lung and pleural metastasis are associated with a higher tumor burden compared to lung metastasis only or pleural metastasis only [25]. Hence, from the perspective of tumor burden, it is reasonable that the results from our study showed the prognosis of simultaneous lung and pleural metastasis were worse.

Studies have suggested that the increased number of metastatic sites would make tumor cells secreted more microenvironment factors, such as vascular endothelial growth factor, which would accelerate tumor progression [14, 26, 27]. This study showed that patients with simultaneous metastasis of lung and pleura had a worse prognosis, and inferred to be associated with the biological characteristics of tumor cells. Furthermore, we inferred that different patterns of metastases of intrathoracic metastatic patterns may be related to the biological characteristics of tumor cells, such as invasiveness and transitivity.

Although all intrathoracic metastases are categorized to M1a by the 8th edition of the TNM classification [7], different patterns of metastases should be taken into account, since they have prognostic relevance for patients with intrathoracic metastatic lung adenocarcinoma.

The major limitation of this study is its retrospective nature. Secondly, the sample size was small for each group. In addition, malignant effusion and pleural metastases are immeasurable lesions, while malignant pericardial effusion is also a type of intrathoracic metastasis. However, the number of such patients was too few to be included in this analysis.

In conclusion, the prognosis for different metastatic patterns of intrathoracic metastasis is distinct in EGFR-mutant lung adenocarcinoma patients, indicating that M1a should be refined.

\section{Abbreviations}

EGFR: epidermal growth factor receptor; CI: confidence interval; HR: hazard ratio; OS: overall survival; NSCLC: non-small cell lung cancer; TNM: tumor size, lymph node metastasis and distant metastasis; TKIs: tyrosine kinase inhibitors; LCT: local consolidative therapy; CT: computed tomography; FDG: fluorodeoxyglucose; PFS: progression-free survival.

\section{Supplementary Material}

Supplementary figures.

http://www.jcancer.org/v10p1254s1.pdf

\section{Acknowledgments}

This study was supported by the National Natural Science Foundation of China (No.81502450) and Science and Technology Commission of Shanghai Municipality, China (No.18441904700). The funding agencies played no role in the design or conduct of this research.

\section{Compliance with Ethical Standards}

\section{Ethical approval}

Investigations involving human patients in this study were performed in accordance with the principles of the Declaration of Helsinki and with the ethical standards of the institutional and/or national research committee.

\section{Informed consent}

Informed consent was obtained from all study participants.

\section{Competing Interests}

The authors have declared that no competing interest exists.

\section{References}

1. Siegel RL, Miller KD, Jemal A. Cancer statistics, 2016. CA Cancer J Clin. 2016; 66: 7-30

2. Torre LA, Bray F, Siegel RL, et al. Global cancer statistics, 2012. CA Cancer J Clin. 2015; 65: 87-108.

3. Chermiti Ben Abdallah F, Ben Ali G, Sadok Boudaya M, et al. Treatment and prognosis of advanced stage non-small-cell lung cancer. Rev Mal Respir. 2014; 31: $214-20$.

4. Carnio S, Novello S, Mele T, et al. Extending survival of stage IV non-small cell lung cancer. Semin Oncol. 2014; 41: 69-92.

5. Paesmans M, Sculier JP, Libert $P$, et al. Prognostic factors for survival in advanced non-small-cell lung cancer: univariate and multivariate analyses including recursive partitioning and amalgamation algorithms in 1,052 patients. The European Lung Cancer Working Party. J Clin Oncol. 1995; 13: 1221-30.

6. Woodard GA, Jones KD, Jablons DM. Lung Cancer Staging and Prognosis. Cancer Treat Res. 2016; 170: 47-75

7. Goldstraw P, Chansky K, Crowley J, et al. The IASLC Lung Cancer Staging Project: Proposals for Revision of the TNM Stage Groupings in the Forthcoming (Eighth) Edition of the TNM Classification for Lung Cancer. J Thorac Oncol. 2016; 11: 39-51.

8. Stenbygaard LE, Sorensen JB, Olsen JE. Metastatic pattern in adenocarcinoma of the lung. An autopsy study from a cohort of 137 consecutive patients with complete resection. J Thorac Cardiovasc Surg. 1995; 110: 1130-5.

9. Sanchez de Cos Escuin J, Abal Arca J, Melchor Iniguez R, et al. Tumor, node and metastasis classification of lung cancer--M1a versus M1b--analysis of M descriptors and other prognostic factors. Lung Cancer. 2014; 84: 182-9.

10. Eberhardt WE, Mitchell A, Crowley J, et al. The IASLC Lung Cancer Staging Project: Proposals for the Revision of the M Descriptors in the Forthcoming Eighth Edition of the TNM Classification of Lung Cancer. J Thorac Oncol. 2015; 10: 1515-22. 
11. He YY, Zhang XC, Yang JJ, et al. Prognostic significance of genotype and number of metastatic sites in advanced non-small-cell lung cancer. Clin Lung Cancer. 2014; 15: 441-7.

12. Warren GW, Cummings KM. Tobacco and lung cancer: risks, trends, and outcomes in patients with cancer. Am Soc Clin Oncol Educ Book. 2013: 359-64.

13. Molina JR, Yang P, Cassivi SD, et al. Non-small cell lung cancer: epidemiology, risk factors, treatment, and survivorship. Mayo Clin Proc. 2008; 83: 584-94.

14. Farhat FS, Tfayli A, Fakhruddin N, et al. Expression, prognostic and predictive impact of VEGF and bFGF in non-small cell lung cancer. Crit Rev Oncol Hematol. 2012; 84: 149-60.

15. Joo JW, Hong MH, Shim HS. Clinical characteristics of T790M-positive lung adenocarcinoma after resistance to epidermal growth factor receptor-tyrosine kinase inhibitors with an emphasis on brain metastasis and survival. Lung Cancer. 2018; 121: $12-7$.

16. Zhang Y, Kang S, Fang W, et al. Impact of smoking status on EGFR-TKI efficacy for advanced non-small-cell lung cancer in EGFR mutants: a meta-analysis. Clin Lung Cancer. 2015; 16: 144-51.

17. Zhou $\mathrm{C}, \mathrm{Wu} \mathrm{YL}, \mathrm{Chen} \mathrm{G}$, et al. Erlotinib versus chemotherapy as first-line treatment for patients with advanced EGFR mutation-positive non-small-cell lung cancer (OPTIMAL, CTONG-0802): a multicentre, open-label, randomised, phase 3 study. Lancet Oncol. 2011; 12: 735-42.

18. Wang H, Huang J, Yu X, et al. Different efficacy of EGFR tyrosine kinase inhibitors and prognosis in patients with subtypes of EGFR-mutated advanced non-small cell lung cancer: a meta-analysis. J Cancer Res Clin Onco. 2014; 140: 1901-9.

19. Memon A, Zawadzki ZA. Malignant effusions: diagnostic evaluation and therapeutic strategy. Curr Probl Cancer. 1981; 5: 1-30.

20. Postmus PE, Brambilla E, Chansky K, et al. The IASLC Lung Cancer Staging Project: proposals for revision of the $\mathrm{M}$ descriptors in the forthcoming (seventh) edition of the TNM classification of lung cancer. J Thorac Oncol. 2007; 2: 686-93.

21. Kim YK, Lee HY, Lee KS, et al. Dry pleural dissemination in non-small cell lung cancer: prognostic and diagnostic implications. Radiology. 2011; 260: 568-74.

22. Shim SS, Lee KS, Kim BT, et al. Integrated PET/CT and the dry pleural dissemination of peripheral adenocarcinoma of the lung: diagnostic implications. J Comput Assist Tomogr. 2006; 30: 70-6.

23. Zhang $\mathrm{H}$, Wroblewski $\mathrm{K}, \mathrm{Pu} \mathrm{Y}$. Prognostic value of tumor burden measurement using the number of tumors in non-surgical patients with non-small cell lung cancer. Acta Radiol. 2012; 53: 561-8.

24. Obara $\mathrm{P}, \mathrm{Pu} \mathrm{Y}$. Prognostic value of metabolic tumor burden in lung cancer. Chin J Cancer Res. 2013; 25: 615-22.

25. Cha YK, Lee HY, Ahn MJ, et al. Survival outcome assessed according to tumor burden and progression patterns in patients with epidermal growth factor receptor mutant lung adenocarcinoma undergoing epidermal growth factor receptor tyrosine kinase inhibitor therapy. Clin Lung Cancer. 2015; 16: 228-36.

26. Ishii H, Yazawa T, Sato H, et al. Enhancement of pleural dissemination and lymph node metastasis of intrathoracic lung cancer cells by vascular endothelial growth factors (VEGFs). Lung Cancer. 2004; 45: 325-37.

27. Cheng D, Kong H, Li Y. Prognostic values of VEGF and IL-8 in malignant pleural effusion in patients with lung cancer. Biomarkers. 2013; 18: 386-90. 